\title{
Anxiety and Depression Among Adult Tobacco Users During the COVID-19 Restrictions in India.
}

Shalini Bassi ( $\nabla$ shalini@hriday-shan.org )

HRIDAY

Gaurang P. Nazar

HRIDAY

Nishigandha Joshi

HRIDAY

Nitika Sharma

HRIDAY

Aishwarya Pandian

Bureau of Disese Control, Los Angeles

Deepa Mohan

Madras Diabetes Research Foundation

Sailesh Mohan

Centre for Chronic Disease Control

Shivani Patel

EMORY University

MK Ali

EMORY University

Ann McNeill

King's College London

Nikhil Tandon

All India Institute of Medical Sciences

V Mohan

Madras Diabetes Research Foundation

Dorairaj Prabhakaran

Centre for Chronic Disease Control

Monika Arora

HRIDAY

\section{Research Article}

Keywords: Mental health, Tobacco users, COVID-19, lockdown 
Posted Date: September 24th, 2021

DOl: https://doi.org/10.21203/rs.3.rs-806234/v1

License: (c) (i) This work is licensed under a Creative Commons Attribution 4.0 International License. Read Full License 


\section{Abstract \\ Background}

The world witnessed a highly contagious and deadly disease, COVID-19, towards the end of 2019. India is one of the worst affected countries. We aimed to assess anxiety and depression levels among adult tobacco users and people who recently quit tobacco during COVID - 19 lockdown in India.

\section{Methods}

The study was conducted across two Indian cities, Delhi and Chennai (July-August, 2020) among adult tobacco users $(n=801)$. Telephonic interviews were conducted using validated mental health tools (Patient Health Questionnaire-PHQ-9 and Generalized Anxiety Disorder-GAD-7) to assess the anxiety and depression levels of the participants. Descriptive analysis and multiple logistic regression were used to study the prevalence and correlates of depression and anxiety.

\section{Results}

We found that $20.6 \%$ of tobacco users had depression symptoms (3.9\% moderate to severe); $20.7 \%$ had anxiety symptoms ( $3.8 \%$ moderate to severe). Risk factors associated with depression and anxiety included food, housing, and financial insecurity.

\section{Conclusion}

During COVID-19 lockdown, mental health of tobacco users (primarily women) was associated with food, housing and financial insecurity. The Indian Government rightly initiated several health, social and economic measures to shield the most vulnerable from COVID-19, including a ban on the sale of tobacco products. It is also necessary to prioritize easy access to tobacco cessation and mental health services to such vulnerable populations during pandemic situations.

\section{Background}

The novel Coronavirus or SARS CoV-2, which began in late 2019, has infected more than 25 million people worldwide thus far and still increasing (1). Besides the massive human toll and economic burden on the Indian healthcare system, the pandemic also posed a myriad of challenges for the country's public health system. As the primary preventive strategy, India went under a nationwide lockdown in March 2020 (2). Strict lockdown regulations and, most importantly, the forced social confinement, disrupted the supply chain of essential commodities, affecting the nation's mental health as a whole $(3,4)$. Fear, anxiety, depression, and insomnia were a few common mental health issues detected in the population during the lockdown $(5,6)$. There is a complex relationship between COVID-19 and smoking. A small but 
important association has been identified between smoking and the severity of COVID-19 (7). Considering this, the Government of India issued several advisories to prohibit the use and spitting of tobacco in public places (8). Subsequently, more stringent tobacco control measures were implemented in India such as banning the sale and use of tobacco products in public places (9). Despite the ban, a crosssectional study has pointed out that tobacco products were readily available during this period(10). There are complex and often bidirectional dynamics between substance abuse and mental health problems(11, 12) which are often believed to co-exist (13).

A recent study conducted following the outbreak of COVID-19, suggested increased mental health problems during the pandemic was associated with increased tobacco use as well. A recent study conducted following the outbreak of COVID-19 suggests challenges to mental health during the pandemic were associated with an increase in tobacco usage(14). However, there is conflicting as well scant scientific literature regarding mental health disorders among tobacco users in India, particularly considering the realities of the pandemic.

The pandemic has led to the re-orientation of our socio-political and economic system. While we are trying to cope and adapt to the new normal with all the focus on containing the pandemic, the mental health impact due to the unprecedented situation created during these times remains unaddressed. These challenges pose even a more significant threat, especially in the vulnerable tobacco consumer groups, especially when there is no capacity and networks for provision of psychosocial support during these vulnerable times. Therefore, there is an urgent requirement to understand and address the psychological burden of tobacco users as well. Hence, this cross-sectional study was conducted to assess the prevalence and correlates of anxiety and depression among adult tobacco users during the COVID-19 restrictions in India.

\section{Methods}

\section{Study design, setting, and participants}

A cross-sectional study was conducted in New Delhi and Chennai (India) between July and August 2020. The study was conducted with adult tobacco users $(n=801)$, both males $(n=722)$ and females $(n=79)$. The inclusion criteria being participant's consent to participate, aged 20 years or above, people who can understand Hindi, English, and Tamil, and be a current tobacco user (any form of tobacco). The participants who were suffering from any severe illness, institutionalized, unable to respond the survey, not speak or understand Hindi, English, or Tamil and not willing to provide or record verbal consent were excluded from the study. The participants who used tobacco in any form in the past one month (from the onset of the survey, i.e, in July 2020) or have quit tobacco during past three months (from the onset date of the survey) were included in the survey. The study participants were recruited from the pre-existing cohort of the CARRS study ("Centre for Cardiometabolic Risk Reduction in South Asia-CARRS), a model surveillance system for cardio-metabolic diseases.(15) Considering the large target population (over 
1 million), assuming a $5 \%$ margin of error, with a $95 \%$ confidence level, we estimated a minimum sample size of $\sim 800$ for our study.

\section{Data collection}

The study data were collected through telephonic interviews, administered by a trained research team, using a standardized protocol. The telephonic interview technique was adopted for data collection to counter the spread of COVID-19 and protect all individuals associated. The questionnaires were administered in English, Hindi, or Tamil, based on the participants' preferences. Those eligible to participate were then asked for informed consent. The verbal consent was audio-recorded following the Indian Council of Medical Research's revised guidelines for obtaining consent for biomedical and health research during the COVID-19 pandemic (16). This method was approved by the Ethics Committee. Prior ethics approval for the research involving human subjects was obtained from the Centre for Chronic Disease Control's Institutional Ethics Committee (Reference \# CCDC_IEC_04_2018).

\section{Study instruments and measures}

A validated mental health tool, i.e., the Patient Health Questionnaire-9 (PHQ-9), was used in our study to assess the symptoms of depression and anxiety among tobacco users.(17)(18) Participants assigned each indicator (e.g. little interest or pleasure in doing things) a value based on the frequency of symptoms they experienced over the preceding two weeks, on a 4-point scale - 0 (not at all), 1 (several days), 2 (more than half the days) and 3 (nearly every day). The total score ranged from zero to 27 . The participants were categorized for the severity of depression based on cumulative scores. A score of 4 or lower was dismissed for signs of depression, 5 to 9 fell into mild, 10 to 14 reflected moderate depression, 15 to 19 was moderately severe depression, and anything beyond 20 was severe depression.(17) These scores were further re-coded for analysis; scores 4 or lower were coded as 0 or 'having no symptoms of depression,' and scores $\geq 5$ were coded as 1 or 'with depression symptoms'(19).

Likewise, Generalized Anxiety Disorder-7 (GAD-7) was used to assess self-reported symptoms of anxiety. (20) The study participants ranked each item (e.g. not being able to stop or control worrying) based on the recurrence of symptoms in the previous two weeks on a 4-point scale - 0 (not at all), 1 (several days), 2 (more than half the days) and 3 (nearly every day). The aggregate score ranged from 0 to 21 . Scores of 4 or lower reflected no anxiety, 5 to 9 represented mild anxiety, 10 to 14 indicated moderate anxiety, and 15 to 21 indicated severe anxiety,(21). During analysis, scores 0 to 4 were coded as 0 or 'having no symptoms of anxiety,' and scores $\geq 5$ were coded as 1 or 'with symptoms of anxiety'.

Additional demographic information, namely age, sex, education level, employment status, were gathered. Particulars about the participants' pre-existing comorbidities (e.g. diabetes, hypertension, stroke, cancer) were obtained from the CARRS database. Additional information on variable definitions is presented in supplementary table S1.

\section{STATISTICAL ANALYSIS}


Chi-square test and Fisher's Exact test were used to determine univariate associations between the sociodemographic characteristics and depression, and anxiety. Unpaired (two-sample) t-test was used to compare the mean score of depression and anxiety among male and female participants. The threshold for significance was set at $p<0.05$. The data are displayed as a mean score \pm (SD), proportions, and percentages. Multiple logistic regression analysis was used to determine Odds Ratios (OR) and 95\% Confidence Intervals $(95 \% \mathrm{Cl})$ for associations between dependent variable depression (coded $1=$ depression present, 0 = depression absent) and other predictor variables. Participant's location, sex, age, education, employment status, and other variables like financial status during the lockdown, food, and housing insecurity were treated as independent variables. Similarly, for the other dependent variable, anxiety (coded, $1=$ anxiety present, $0=$ anxiety absent), the same independent variables were used in the regression model. All tests were considered significant at the 0.05 level. The independent variables were examined for multicollinearity. The VIF values were less than ten, indicating no evidence of multicollinearity.(18) The data were analyzed using STATA 13.0 (StataCorp, LP, Texas)(22).

\section{Results}

\section{Study participants' characteristics}

In total, 2,505 adult tobacco users from Delhi $(n=1365)$ and Chennai $(n=1140)$ were approached to participate in our study. A total of 801 tobacco users participated in the survey out of whom, 444 (55.4\%) were from Delhi while 357 (44.6\%) were from Chennai. As the survey was conducted telephonically, a disposition table is used to explain the response rates [Tables S2 and S3]. The gross response rate for the study was $48.4 \%$, the basic response rate was $85.3 \%$ and the response rate calculated using the CASRO Estimator(23) was $60.9 \%$. Roughly $90 \%$ of the adult tobacco users were males, and $87.9 \%$ were in the age group of 25-64 years. The majority (81.2\%) were employed, and $11.5 \%$ had a bachelor's degree and above. The study participants' mean age was 50.5 years, with a range from 25 to 90 years. The majority of tobacco users were smokeless tobacco users (40.5\%), followed by cigarette smokers (38.0\%) and bidi smokers (24.3\%) (Table 1). 
Table 1

Socio-demographic characteristics of the study participants $(n=801)$

\section{Socio-demographic characteristics}

n (\%)

\section{City}

Delhi

$444(55.4)$

Chennai

$357(44.6)$

Sex

Males

$722(90.1)$

Females

$79(9.9)$

Age (in years)

$25-44$

$253(31.6)$

$45-64$

$451(56.3)$

65 and above

$97(12.1)$

\section{Education}

Professional Degree/Post Graduate

Graduate (B.A/B.Sc./B.Com/Diploma)

$75(9.4)$

Secondary School /Intermediary

$249(31.0)$

High school (class V to IX)

$316(39.5)$

Primary School (up to Class IV)

$64(8.0)$

No formal education

$80(10.0)$

\section{Employment Status}

Employed

$650(81.2)$

Student

88 (11.0)

Housewife

29(3.6)

*For Cigarette smokers (Out of $n=801,305$ were cigarette smokers; Out of them 15 participants had recently quit cigarette smoking)

For Bidi smokers $(n=798)$, three observations were missing; Out of them 195 were bidi smokers; of which 10 participants had recently quit bidi smoking.

For Smokeless tobacco users $(n=800)$, one observation was missing; Out of which 324 participants were smokeless tobacco users; of which 13 participants had recently quit smokeless tobacco.

Recently quit tobacco - Participants who had quit tobacco during past three months (from the onset date of survey). 


\section{Socio-demographic characteristics}

Retired

Unemployed

\section{Tobacco use*}

Cigarette smokers

Cigarette smokers who recently quit

Bidi smokers $(n=798)$

Bidi smokers who recently quit $(n=195)$

Smokeless tobacco users $(n=800)$

Smokeless tobacco users who recently quit $(n=324)$

Dual Users $\mathrm{n}(\%)$

16(2.0)

$18(2.2)$
$305(38.0)$

15(1.9)

195(24.3)

10(1.2)

$324(40.5)$

$13(1.6)$

$30(3.7)$

*For Cigarette smokers (Out of $n=801,305$ were cigarette smokers; Out of them 15 participants had recently quit cigarette smoking)

For Bidi smokers $(n=798)$, three observations were missing; Out of them 195 were bidi smokers; of which 10 participants had recently quit bidi smoking.

For Smokeless tobacco users $(n=800)$, one observation was missing; Out of which 324 participants were smokeless tobacco users; of which 13 participants had recently quit smokeless tobacco.

Recently quit tobacco - Participants who had quit tobacco during past three months (from the onset date of survey).

\section{Prevalence of depressive symptoms among tobacco users}

The mean PHQ-9 score for the study participants was $2.5 \pm$ (3.4). Of the 763 complete responses, $20.6 \%$ of tobacco users were found to have depression symptoms (PHQ-9 score $>4$ ). About $16.7 \%$ of participants reported mild depression symptoms (PHQ-9 score between 5-9), 2.9\% experienced moderate depression (PHQ-9 score between 10-14), 0.7\% had moderately severe depression (PHQ-9 score 15-19), and $0.3 \%$ had severe depression (PHQ-9 score 20-27) (Fig. 1). The mean depression score for females was $3.2 \pm(3.1)$, which was significantly higher than that for males $2.4 \pm(3.4) .(p=0.02)$.

Figure 2 represents the distribution of the tobacco users according to the GAD-7 score. The mean GAD-7 score for the study participants was $2.4(S D \pm 3.2)$. Of the 774 respondents responding to anxiety questions, $20.7 \%$ had a GAD score greater than 4 . The prevalence of mild anxiety (GAD score $5-9$ ) was $16.9 \%, 3.1 \%$ had moderate anxiety symptoms (GAD score $10-14$ ), and $0.7 \%$ had severe anxiety symptoms (GAD score 15-21). When analyzed along gender lines, the mean anxiety score for females was $3 \pm(3.2)$, significantly higher than the mean scores for males at $2.3 \pm(3.20)(p=0.02)$.

Table 2 shows the univariate associations of depression and anxiety with the socio-demographic as well as other independent variables. The symptoms of anxiety appeared in $27 \%$ and depression in $25 \%$ of the 
study participants, who were employed but currently not working, unemployed, or had uncertain employment status. In contrast, among the individuals who were employed and currently working, $17 \%$ experienced depression and $16.9 \%$ experienced anxiety. 
Table 2

Prevalence of depression and anxiety symptoms among tobacco users

\begin{tabular}{|c|c|c|c|c|}
\hline \multirow[t]{3}{*}{ Variables } & $\begin{array}{l}\text { Depression }(\geq 5) \\
(\mathrm{N}=763)\end{array}$ & $\begin{array}{l}P \\
\text { value }\end{array}$ & $\begin{array}{l}\text { Anxiety } \\
(\geq 5)\end{array}$ & $\begin{array}{l}P \\
\text { value }\end{array}$ \\
\hline & \multirow[t]{2}{*}{$\mathrm{n}(\%)$} & & \multicolumn{2}{|l|}{$\begin{array}{l}(N= \\
774)\end{array}$} \\
\hline & & & \multicolumn{2}{|l|}{$\mathrm{n}(\%)$} \\
\hline \multicolumn{5}{|l|}{ Sex } \\
\hline Males $(\mathrm{N}=722)$ & $138(19.1)$ & \multirow[t]{2}{*}{0.384} & $\begin{array}{l}138 \\
(19.1)\end{array}$ & \multirow[t]{2}{*}{0.071} \\
\hline Females $(\mathrm{N}=79)$ & $18(22.7)$ & & $\begin{array}{l}22 \\
(27.8)\end{array}$ & \\
\hline \multicolumn{5}{|l|}{ Age category (in years) } \\
\hline $25-44(N=253)$ & $51(20.1)$ & \multirow[t]{3}{*}{0.896} & $\begin{array}{l}57 \\
(22.5)\end{array}$ & \multirow[t]{3}{*}{0.552} \\
\hline $45-64(N=451)$ & $86(19)$ & & $\begin{array}{l}85 \\
(18.8)\end{array}$ & \\
\hline 65 years and above $(\mathrm{N}=97)$ & 19 (19.6) & & $\begin{array}{l}18 \\
(18.6)\end{array}$ & \\
\hline
\end{tabular}

\section{Education}

Professional degree/post graduate $(\mathrm{N}=17)$

$1(5.8)$

$0.851 \quad 1(5.8) \quad 0.523$

Graduate $(\mathrm{N}=75)$

$15(20)$

11

Secondary School /Intermediary $(\mathrm{N}=249)$

$48(19.2)$

52

High school $(\mathrm{N}=316)$

$64(20.3)$

66

Primary School $(\mathrm{N}=64)$

$12(18.8)$

12

Illiterate $(\mathrm{N}=80)$

16(20)

18

\section{Employment status}

Employed and currently working $(\mathrm{N}=551)$

$94(17)$

0.009

93 


\begin{tabular}{|c|c|c|c|c|}
\hline \multirow[t]{3}{*}{ Variables } & $\begin{array}{l}\text { Depression }(\geq 5) \\
(\mathrm{N}=763)\end{array}$ & $\begin{array}{l}P \\
\text { value }\end{array}$ & $\begin{array}{l}\text { Anxiety } \\
(\geq 5)\end{array}$ & $\begin{array}{l}P \\
\text { value }\end{array}$ \\
\hline & \multirow[t]{2}{*}{$\mathrm{n}(\%)$} & & \multirow{2}{*}{\multicolumn{2}{|c|}{$\begin{array}{l}(\mathrm{N}= \\
774) \\
\mathrm{n}(\%)\end{array}$}} \\
\hline & & & & \\
\hline $\begin{array}{l}\text { Employed but currently not working/ unemployed/ } \\
\text { uncertain employment }\end{array}$ & \multirow{2}{*}{\multicolumn{2}{|c|}{$62(25)$}} & \multirow{2}{*}{\multicolumn{2}{|c|}{$67(27)$}} \\
\hline$(N=248)$ & & & & \\
\hline \multicolumn{5}{|l|}{ Financial status } \\
\hline Doing alright $(\mathrm{N}=188)$ & $18(9.6)$ & \multirow{2}{*}{$\hat{0} .001$} & $15(8)$ & \multirow{2}{*}{$\hat{0.001}$} \\
\hline $\begin{array}{l}\text { Just about getting by/ finding it quite difficult }(\mathrm{N}= \\
\text { 568) }\end{array}$ & $129(22.7)$ & & $\begin{array}{l}140 \\
(24.6)\end{array}$ & \\
\hline \multicolumn{5}{|l|}{ Lockdown status } \\
\hline Complete or partial lockdown $(\mathrm{N}=481)$ & $89(18.5)$ & \multirow[t]{2}{*}{0.609} & $\begin{array}{l}84 \\
(17.5)\end{array}$ & \multirow[t]{2}{*}{0.706} \\
\hline No lockdown $(\mathrm{N}=94)$ & $19(20.2)$ & & $\begin{array}{l}18 \\
(19.1)\end{array}$ & \\
\hline \multicolumn{5}{|c|}{ Food Security (ability to buy food during COVID-19 lockdown) } \\
\hline Often $(N=598)$ & $63(10.5)$ & \multirow{2}{*}{$\hat{0} .001$} & $93(16)$ & \multirow{2}{*}{$\dot{0.001}$} \\
\hline Sometimes/ never(N = 192) & $44(23)$ & & $\begin{array}{l}66 \\
(34.3)\end{array}$ & \\
\hline \multicolumn{5}{|l|}{ House security (worried about paying rent or house loan) } \\
\hline No $(N=501)$ & $71(14.2)$ & \multirow[t]{3}{*}{$\hat{0} .001$} & $\begin{array}{l}61 \\
(12.1)\end{array}$ & \multirow[t]{3}{*}{$<.001$} \\
\hline Sometimes $(\mathrm{N}=83)$ & $20(24)$ & & $20(24)$ & \\
\hline Yes $(N=213)$ & $65(30.5)$ & & $79(37)$ & \\
\hline \multicolumn{5}{|l|}{ Worried about getting evicted from house } \\
\hline No $(N=646)$ & $94(14.6)$ & \multirow[t]{3}{*}{$\hat{0} .001$} & $\begin{array}{l}86 \\
(13.3)\end{array}$ & \multirow[t]{3}{*}{$\begin{array}{l}<.001 \\
0.00\end{array}$} \\
\hline Sometimes $(N=60)$ & $22(36.6)$ & & $\begin{array}{l}28 \\
(46.6)\end{array}$ & \\
\hline Yes $(N=91)$ & $39(42.8)$ & & $\begin{array}{l}46 \\
(50.5)\end{array}$ & \\
\hline
\end{tabular}

${ }^{*}$ Chi square test and Fisher's Exact Test; For depression ( $\left.n=763\right)$ - 38 Observations were missing; For Anxiety $(n=774)-27$ Observations were missing 


\begin{tabular}{|c|c|c|c|c|}
\hline \multirow[t]{3}{*}{ Variables } & $\begin{array}{l}\text { Depression }(\geq 5) \\
(\mathrm{N}=763)\end{array}$ & $\begin{array}{l}\mathrm{P} \\
\text { value }\end{array}$ & $\begin{array}{l}\text { Anxiety } \\
(\geq 5)\end{array}$ & $\begin{array}{l}P \\
\text { value }\end{array}$ \\
\hline & \multirow[t]{2}{*}{ n (\%) } & & \multirow{2}{*}{\multicolumn{2}{|c|}{$\begin{array}{l}(\mathrm{N}= \\
774) \\
\mathrm{n}(\%)\end{array}$}} \\
\hline & & & & \\
\hline \multicolumn{5}{|l|}{ Cigarette use } \\
\hline Yes $(N=305)$ & $55(18)$ & \multirow[t]{2}{*}{0.365} & $\begin{array}{l}57 \\
(18.7)\end{array}$ & \multirow[t]{2}{*}{0.422} \\
\hline No $(N=496)$ & $101(20.4)$ & & $\begin{array}{l}103 \\
(20.8)\end{array}$ & \\
\hline \multicolumn{5}{|l|}{ Bidi use } \\
\hline Yes(N = 195) & $32(16.4)$ & \multirow[t]{2}{*}{0.270} & $\begin{array}{l}30 \\
(15.4)\end{array}$ & \multirow[t]{2}{*}{0.091} \\
\hline No $(N=603)$ & $122(20.2)$ & & $\begin{array}{l}128 \\
(21.2)\end{array}$ & \\
\hline \multicolumn{5}{|c|}{ Smokeless tobacco use } \\
\hline Yes $(N=324)$ & $67(20.7)$ & \multirow[t]{2}{*}{0.558} & $71(22)$ & \multirow[t]{2}{*}{0.313} \\
\hline No $(N=476)$ & 89 (18.7) & & $\begin{array}{l}89 \\
(18.7)\end{array}$ & \\
\hline $\begin{array}{l}\text { *Chi square te } \\
\text { Anxiety }(n=7)\end{array}$ & $n(n=763)-38 O b$ & & ere mis & ; For \\
\hline
\end{tabular}

Individuals experiencing poor financial status displayed a marked distinction in depression (22.7\%) and anxiety symptoms (24.6\%) when compared to those who claimed to be financially secure and stable during the pandemic-depression (9.6\%) and anxiety (8\%). Tobacco users who reported the ability to buy food sometimes or never during COVID-19 lockdown had significantly higher rates of depression (23\%) and anxiety symptoms (34.3\%) as opposed to $(10.5 \%)$ and $(16 \%)$ in people who could often buy food during the pandemic. Of the individuals who were worried about paying house rent or loans, $30.5 \%$ claimed to have depression, and $37 \%$ reported anxiety symptoms, starkly distinguished from individuals who were not worried (14.2\%) had depression and $(12.1 \%)$ had anxiety respectively. The participants who worried about being evicted from homes were significantly more depressed (42.8\%) as compared to those who were not worried (14.6\%) and reported anxiety symptoms in $50.5 \%$ of participants as compared to those who were not worried (13.3\%). We observed that the prevalence of depression and anxiety symptoms did not change with the presence of lockdown restrictions or by type of containment zones ( $P$ $>0.05)$.

We observed that the presence of depression and anxiety symptoms did not change with the type of tobacco use and did not differ significantly between single tobacco product users and dual/multiple 
tobacco product users. The people who had recently quit tobacco did not display marked distinction in depression and anxiety symptoms than current tobacco users.

Table 3 represents findings from the logistic regression analysis assessing predictors of depression and anxiety in adult tobacco users during COVID-19. In females, the odds of anxiety were twice that in males $(\mathrm{OR}=2,95 \% \mathrm{Cl} 1.0-3.8)$. The risk of depression was 1.8 times and anxiety 2.2 times among participants who were financially just about getting by or finding it quite difficult as compared to those who were financially doing all right $(\mathrm{OR}=1.8,95 \% \mathrm{Cl} 1.0-3.1$ and $\mathrm{OR}=2.2,95 \% \mathrm{Cl} 1.2-4.0$, respectively). The risk of being depressed was 2.3 times and being anxious, 1.9 times higher in people who could buy food only sometimes or never than in the people who could buy food often during the lockdown (OR $2.3,95 \% \mathrm{Cl} 1.4$ -3.7 and OR $1.9,95 \% \mathrm{Cl} 1.1-3.0)$, respectively. 
Table 3

Predictors of depression and anxiety in adult tobacco users during COVID-19*

\section{Covariates}

\section{Depression $(n=$ 715) \\ OR $(95 \% \mathrm{Cl})$ \\ Anxiety $(\mathrm{n}=$ 725) \\ OR $(95 \% \mathrm{Cl})$}

\section{City}

Chennai

Delhi

Sex

Male

Female

Age Category

25-44

$45-64$

65 years and above

\section{Education}

Professional degree/post graduate

Graduate

Secondary School / Intermediary

High school

Primary School

Illiterate

\section{Employment status}

Employed and currently working

Employed but currently not working/ unemployed / uncertain employment
(Ref)

$1.3(0.8-2.0)$

(Ref)

$1.2(0.7-1.8)$
(Ref)

$1.3(0.6-2.6)$
(Ref)

$2(1.0-3.8)$
(Ref)

$1.0(0.7-1.6)$

$1.0(0.5-2.1)$
(Ref)

$0.8(0.6-1.3)$

$1.0(0.5-$

2.1)
(Ref)

$\begin{array}{ll}2.6(0.3-21.8) & 1.4(0.2- \\ & 12.4)\end{array}$

$1.9(0.2-15.5)$

1.8(0.2-14.3)

$1.8(0.2-16.1)$

$1.4(0.2-12.6)$

(Ref)

(Ref)

$1.0(0.7-1.6)$
13.8)

$1.3(0.1-$ 10.9)

$1.2(0.1-$ 11.3)

$0.9(0.1-8.0)$

*Estimated using logistic regression analyses separately for the outcomes (depression and anxiety) after adjusting for city, sex, age, education, employment status, financial status, food security and house security during the lockdown 


\section{Covariates}

Depression $(\mathrm{n}=$

715)

OR $(95 \% \mathrm{Cl})$
Anxiety $(\mathrm{n}=$ 725)

OR $(95 \% \mathrm{Cl})$

\section{Financial status}

Doing alright

(Ref)

Just about getting by/ finding it quite difficult

$1.8(1.0-3.1)$

$2.2(1.2-4.0)$

Food Security (ability to buy food during COVID-19 lockdown)

Often

(Ref)

Sometimes/ never

$2.3(1.4-3.7)$

$1.9(1.1-3.0)$

House security (worried about paying rent or house loan)

No

(Ref)

(Ref)

Sometimes

$0.8(0.4-1.8)$

$0.8(0.3-1.7)$

Yes

$1.1(0.6-2.0)$

$1.6(0.9-2.7)$

Worried about getting evicted from house

No

(Ref)

(Ref)

Sometimes

$3.0(1.5-6.2)$

4.5(2.2 - 9.3)

Yes

$3.8(2.0-7.0)$

$4.5(2.4-8.4)$

*Estimated using logistic regression analyses separately for the outcomes (depression and anxiety) after adjusting for city, sex, age, education, employment status, financial status, food security and house security during the lockdown

For participants who were only 'sometimes worried about getting evicted', the risk of depression was 3 times and anxiety was 4.5 times more than those who were not worried about getting evicted from the house (OR 3, 95\% Cl $1.5-6.2$ and OR $4.5,95 \% \mathrm{Cl} 2.2-9.3)$. Furthermore, people who were regularly worried about getting evicted had higher odds of depression (3.8 times) and anxiety (4.5 times) than those who did not worry about evictions (OR 3.8, 95\% Cl 2.0 - 7.0 and OR 4.5, 95\% Cl $2.4-8.4$, respectively).

\section{Discussion}

The COVID-19 pandemic has caused unprecedented changes around the globe in a very short time, affecting all the facets of people's lives. This study assessed the levels of psychological distress measured in terms of depression and anxiety in tobacco users and people who had recently quit tobacco during the COVID-19 pandemic in India. We found that, $20.5 \%$ of study participants had symptoms of depression with the majority experiencing mild depression, and $3.9 \%$ of participants experienced moderate to severe depression. Similarly, anxiety was present in $20.7 \%$ of tobacco users, with $3.7 \%$ 
experiencing moderate to severe symptoms. The prevalence of anxiety and depression was lower in our study as compared to the other studies conducted among the general population in India and globally during the COVID-19 times (24-26). This could be because our study was limited to tobacco users and people who had recently quit tobacco in two large metropolitan cities of India and was conducted at much later stage of the COVID-19, when gradual easing of lockdown was in process. This was the period when there was relaxation in restrictions which might have led to a relative sense of normalcy. We did not find any association between tobacco use and anxiety and depression symptoms, which could be attributed to the fact that tobacco products were easily available during this time despite the ban.(10)

The findings of our study showed an association between depression and anxiety symptoms (score $\geq 5$ ) with the present unemployment, financial, food and housing insecurity. Similar findings were observed in an online study conducted in India during the pandemic among the general population where the financial status of the family and ability to access essential supplies were seen to be linked with anxiety and depression.(27)

Gender was found to be significantly associated with anxiety disorder. When the depression and anxiety scores were analysed along gender lines, women had significantly higher scores than males. Women were found to be twice more likely to have anxiety symptoms compared to males. These findings are consistent with studies conducted in Bangladesh and India during the pandemic. $(24,26)$ This might be attributed to the fact that women inadvertently bear the brunt of increased domestic responsibilities during the pandemic and also were more likely to face violence or abuse during the pandemic and had limited access to resources and healthcare.(28)

India's mental health care system, which is a part of the general health care system, has suffered from sub-optimal investment and was already over-extended and under-resourced even before the advent of the pandemic. It is mostly curative in nature concentrating on providing tertiary care. COVID-19 has caused widespread social and economic turmoil across the globe. Although the Government of India has taken several initiatives to protect the most vulnerable population, there are definite gaps in its reach, nature as well level of protection it offers. Financial insecurities take a definite toll on the mental health of individuals as seen in our study. The pandemic has accentuated the need for a comprehensive social security net now more than ever. This crisis should be seen as an opportunity to rebuild a strong resilient health system to broaden the canopy of universal health coverage. Easy access to tobacco cessation services must be provided as it is crucial for both the physical and mental health of tobacco users.

\section{Strengths and limitations of the study}

The strength of our study lies in the fact that it tries to explore the effect of life altering situations during the COVID-19 pandemic on mental health among tobacco users in India. Our questionnaire was designed based on previously validated STOP survey.(29) There is a dearth of literature on mental health among tobacco users in the country. Possible limitations of this study include use of telephonic interviews for data collection. This did not allow building up of rapport with the participants which is especially crucial

Page 16/22 
in sensitive topics like mental health. This may not have characterized mental health status of the people with accuracy of structured face to face interviews. There is also the possibility of recall bias because participants may not accurately recall having depression and anxiety symptoms in preceding two weeks. There is also a possibility of depression and anxiety among the participants due to some other reasons not captured through our survey. There are predictive limitations because the study is cross-sectional so causal inferences cannot be drawn. We did not have pre-COVID data on depression and anxiety levels of the study participants to compare. We did not have control group of non-tobacco users so could not assess if tobacco use was one of the correlates of mental health status. The study was conducted across two cities of India namely, Delhi and Chennai and hence, the findings may not be generalized to entire Indian population.

\section{Conclusion}

Although the study findings were more conservative than we expected, we found that during the COVID19 lockdown the mental health status of tobacco users, primarily women, was associated with food and housing insecurity, and financial uncertainty during the pandemic. In order to protect the most vulnerable from COVID-19, India's Government initiated several much-needed health, social and economic measures, including the ban on the sale of tobacco products to circumvent the diversion of valuable resources during this crisis. There is also an urgent need to prioritize easy access to tobacco cessation and mental health services to mitigate the effects of the pandemic on the health of the vulnerable population in a long run.

\section{Abbreviations}

PHQ 9 - Patient Health Questionnaire-9

GAD 7- Generalized Anxiety Disorder-7

SD- Standard deviation

Cl- Confidence interval

$\mathrm{OR}$ - Odds ratio

\section{Declarations}

\section{Ethics approval and consent to participate}

Prior ethics approval for research involving human subjects for this study was obtained from the Centre for Chronic Disease Control's Institutional Ethics Committee (Reference \# CCDC_IEC_04_2018). Informed consent was sought from eligible participants. A verbal consent was audio-recorded following the Indian Council of Medical Research's revised guidelines for obtaining consent for biomedical and health 
research during the COVID-19 pandemic. Participants who were suffering from any severe illness, institutionalized, unable to respond the survey, and not willing to provide or record verbal consent were excluded from the study. All data was collected in accordance with guidelines, protocols and methods approved by the CCDC's Ethics Committee. All the necessary measures to safeguard participants' anonymity and confidentiality of information were respected.

\section{Consent for Publication}

Not Applicable

\section{Availability of data and materials}

The datasets used and analysed for the current study are available from the Principal Investigator/Corresponding author of this study on reasonable request.

\section{Competing Interest}

The authors declare that they have no competing interests.

\section{Funding}

The activities and results presented in this publication were supported by the following grants: COVID-19 and Tobacco Project, funded from the University of Edinburgh's Scottish Funding Council Global Challenges Research Fund (GCRF) allocation and the Tobacco Control Capacity Programme (MR/P027946/2) supported by UK Research and Innovation (UKRI) with funding from the Global Challenges Research Fund."

\section{AUTHORS' CONTRIBUTIONS STATEMENT}

MA, GPN and SB conceptualized the study. SB and GPN led the data collection efforts and contributed to study administration. SB, GPN, NJ, NS, AP contributed to data management, analysis, interpretation of results, and drafting the manuscript. DM, SM, SP, MK, AM, NT, DP and MA provided technical inputs on data analysis, interpretation of results and reviewed the manuscript critically for intellectual contents. All the authors approved the final version of the manuscript and are accountable for the accuracy and integrity of any part of the work.

\section{ACKNOWLEDGEMENT}

Not applicable

\section{References}

1. World Health Organization WHO Coronavirus Disease (COVID-19) Dashboard I WHO Coronavirus Disease (COVID-19) Dashboard [Internet]. [cited 2020 Sep 7]. Available from: https://covid19.who.int/ 
2. Suri M, Gupta S, Kottasová I. India, population 1.3 billion, orders "complete" coronavirus lockdown. CNN [Internet]. 2020 [cited 2020 Nov 4]; Available from: https://edition.cnn.com/2020/03/24/asia/india-lockdown-coronavirus-intl/index.html

3. Sharma AJ, Subramanyam MA. Psychological impact of Covid-19 lockdown in India: Different strokes for different folks. medRxiv. medRxiv; 2020.

4. Dalal P, Roy D, Choudhary P, Kar S, Tripathi A. Emerging mental health issues during the COVID-19 pandemic: An Indian perspective. Indian J Psychiatry [Internet]. 2020 Sep 1 [cited 2021 Apr 26];62(9):354. Available from: http://www.indianjpsychiatry.org/text.asp?2020/62/9/354/296512

5. Roy A, Singh AK, Mishra S, Chinnadurai A, Mitra A, Bakshi O. Mental health implications of COVID-19 pandemic and its response in India. Int J Soc Psychiatry [Internet]. 2020 [cited 2021 Apr 27]; Available from: /pmc/articles/PMC7468668/

6. Walter D. Implications of Covid-19 for Labour and Employment in India. Indian J Labour Econ. 2020 Oct 1;63(1):47-51.

7. Simons D, Shahab L, Brown J, Perski O. The association of smoking status with SARS-CoV-2 infection, hospitalization and mortality from COVID-19: a living rapid evidence review with Bayesian meta-analyses (version 7). Addiction. 2020 Oct;

8. Don't Consume or Spit Smokeless Tobacco Products in Public Places: ICMR. NEWS18 [Internet]. 2020May14 [cited 2020Sep7]; Available from: https://www.news18.com/news/india/dont-consumeor-spit-smokeless-tobacco-products-in-public-places-icmr-2564739.html

9. 28 states, UTs ban smokeless tobacco products, spitting due to coronavirus. The Economic Times [Internet]. 2020May10 [cited 2020Sep7]; Available from: https://economictimes.indiatimes.com/news/politics-and-nation/28-states-uts-ban-smokelesstobacco-products-spitting-due-to-coronavirus/articleshow/75657382.cms

10. Veeraiah S, Sudhakar R, Tripathy JP, Sankar D, Usharani A, Ramakrishnan S, et al. Tobacco use and quitting behaviour during COVID-19 lockdown. Int J Tuberc Lung Dis [Internet]. 2020 [cited 2021 Jun 30]; Available from: http://dx.doi.org/10.5588/ijtld.20.0728

11. Vorspan F, Mehtelli W, Dupuy G. Anxiety and Substance Use Disorders: Co-occurrence and Clinical Issues. 2015;

12. Brook DW, Brook JS, Zhang C, Cohen P, Whiteman M. Drug Use and the Risk of Major Depressive Disorder, Alcohol Dependence, and Substance Use Disorders. Arch Gen Psychiatry [Internet]. 2002 Nov 1;59(11):1039-44. Available from: https://doi.org/10.1001/archpsyc.59.11.1039

13. Brose LS, Brown J, Robson D, McNeill A. Mental health, smoking, harm reduction and quit attempts A population survey in England. BMC Public Health. 2020;20(1):1-9.

14. Chen D. The psychosocial impact of the COVID-19 pandemic on changes in smoking behavior: Evidence from a nationwide survey in the UK. Tob Prev Cessat. 2020 Oct 23;6(October):1-5.

15. Nair M, Ali MK, Ajay VS, Shivashankar R, Mohan V, Pradeepa R, et al. CARRS Surveillance study: design and methods to assess burdens from multiple perspectives. BMC Public Health. 2012;12(1):701. 
16. Indian Council of Medical Research. ICMR National Guidelines for Ethics Committees Reviewing Biomedical and Health Research during COVID-19 pandemic, 2020. https://www.icmr.gov.in/pdf/covid/techdoc/EC_Guidance_COVID19_06052020.pdf

17. Kroenke K, Spitzer RL, Williams JBW. The PHQ-9: Validity of a brief depression severity measure. J Gen Intern Med. 2001;16(9):606-13.

18. Spitzer RL, Kroenke K, Williams JBW. Validation and utility of a self-report version of PRIME-MD: The PHQ Primary Care Study. J Am Med Assoc. 1999 Nov;282(18):1737-44.

19. Thour A, Das S, Sehrawat T, Gupta Y. Depression among patients with diabetes mellitus in North India evaluated using patient health questionnaire-9. Indian J Endocrinol Metab. 2015;19(2):252-5.

20. Löwe B, Decker O, Müller S, Brähler E, Schellberg D, Herzog W, et al. Validation and standardization of the Generalized Anxiety Disorder Screener (GAD-7) in the general population. Med Care. 2008;26674.

21. Spitzer RL, Kroenke K, Williams JBW, Löwe B. A brief measure for assessing generalized anxiety disorder: The GAD-7. Arch Intern Med [Internet]. 2006 May 22;166(10):1092-7. Available from: https://jamanetwork.com/

22. StataCorp. 2013. Stata Statistical Software: Release 13. College Station, TX: StataCorp LP.

23. Massey JT. Estimating the response rate in a telephone survey with screening. In: Proceedings of the section on survey research methods. American Statistical Association Alexandria, VA; 1995. p. 6737.

24. Azdi Z Al, Islam K, Chowdhury AH, Ahmed HU, Alam R, Hussain AHME, et al. The Magnitude of Depression and Anxiety During COVID 19: An Online Survey Among Adults in Bangladesh Table of Contents. 2020;

25. Choi EPH, Hui BPH, Wan EYF. Depression and anxiety in Hong Kong during covid-19. Int J Environ Res Public Health. 2020 May 5;17(10).

26. Gopal A, Sharma AJ, Subramanyam MA. Dynamics of psychological responses to COVID-19 in India: A longitudinal study. Vickers K, editor. PLoS One. 2020 Oct;15(10):e0240650.

27. Rehman U, Shahnawaz MG, Khan NH, Kharshiing KD, Khursheed M, Gupta K, et al. Depression, Anxiety and Stress Among Indians in Times of Covid-19 Lockdown. Community Ment Health J. 2020;1.

28. Maiti T, Rai B, Biswas T. Women mental Health during COVID 19 and Lock down: A brief narrative and Introspection. iMedPub Journals [Internet]. 2020 [cited 2020 Dec 1]; Available from: http://www.ptinews.com/news/11348195_Domestic-abuse-

29. STOP survey (Studying Tobacco users Of Pakistan (STOP): repeated cross-sectional and longitudinal survey) [Internet]. [cited 2020 Dec 15]. Available from: http://theinitiative.org.pk/stopsurvey-studying-tobacco-users-of-pakistan-stop-repeated-cross-sectional-and-longitudinal-survey/

\section{Figures}




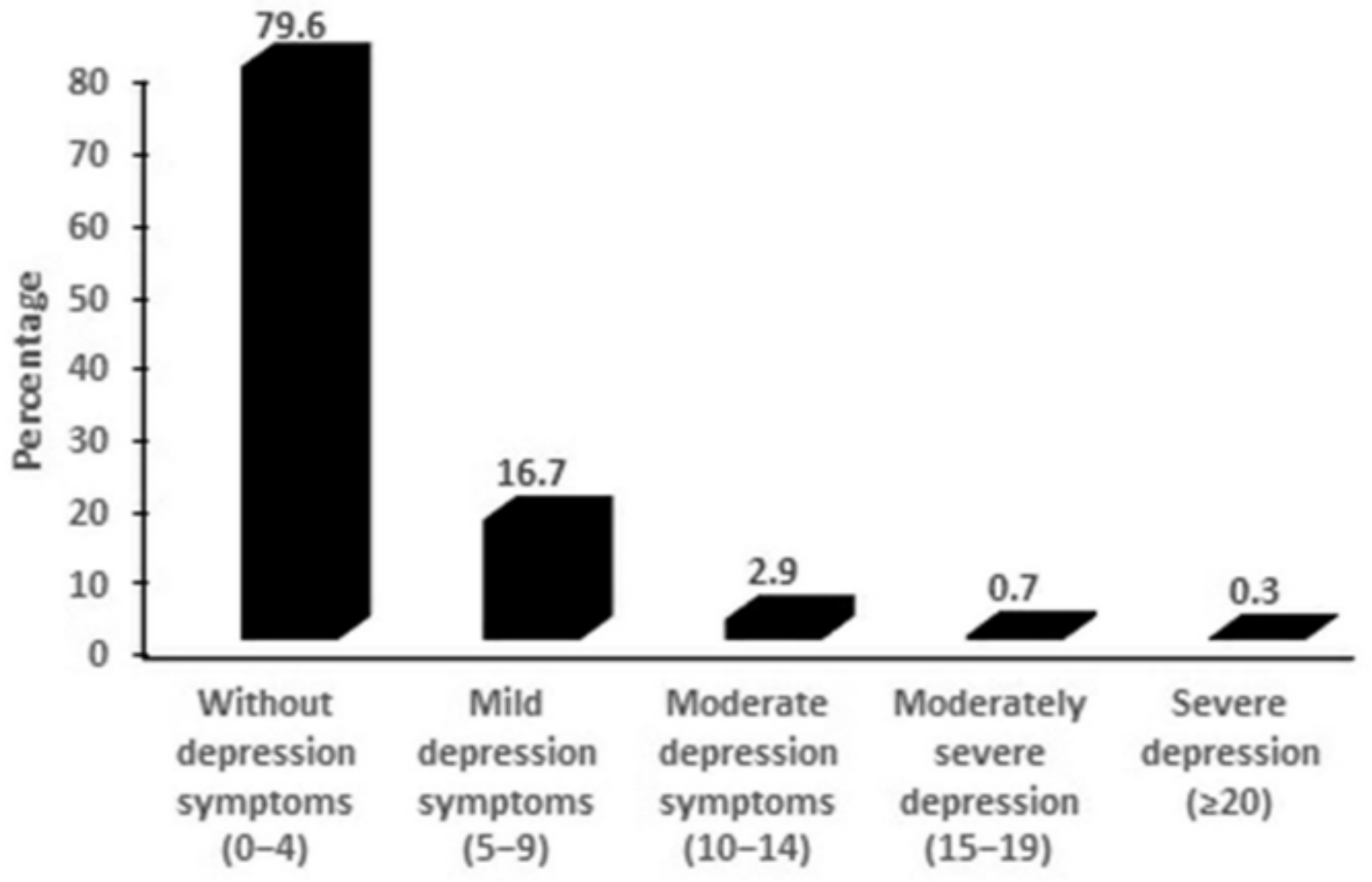

Figure 1

Prevalence of depression symptoms among tobacco users during COVID-19 pandemic 


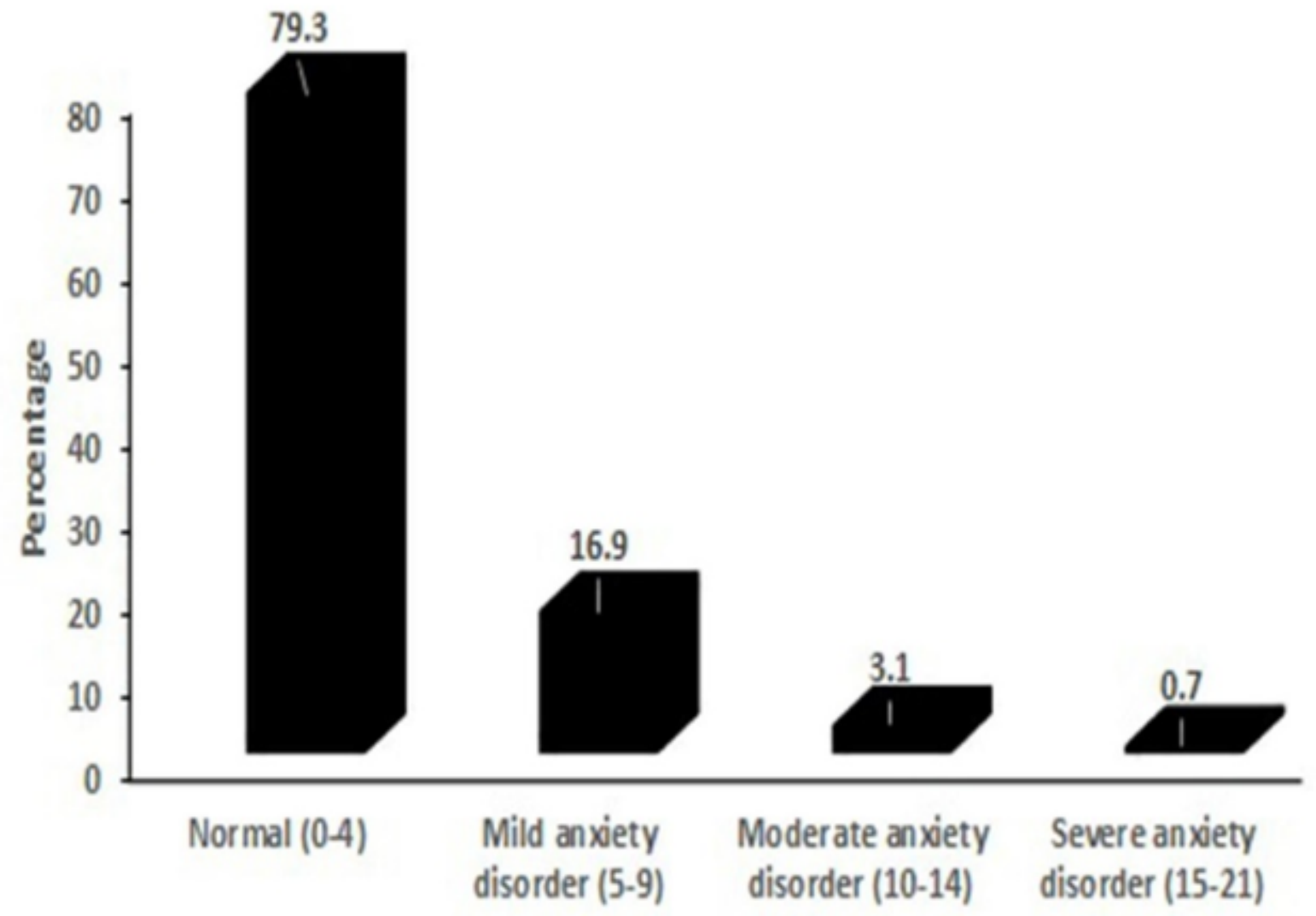

Figure 2

Prevalence of anxiety symptoms among tobacco users during COVID-19 pandemic

\section{Supplementary Files}

This is a list of supplementary files associated with this preprint. Click to download.

- Supplementaryfilementalhealthpaper.docx 